\title{
Association of endothelial dysfunction with endothelin, nitric oxide and eNOS Glu298Asp gene polymorphism in coronary artery disease
}

\author{
Vandana Saini ${ }^{\mathrm{a}, *}$, M.K. Bhatnagar ${ }^{\mathrm{b}}$ and Jayashree Bhattacharjee ${ }^{\mathrm{b}}$ \\ ${ }^{a}$ Department of Biochemistry, Lady Hardinge Medical College and Associated hospitals, New Delhi, India \\ ${ }^{\mathrm{b}}$ Department of Medicine, Lady Hardinge Medical College and Associated hospitals, New Delhi, India
}

\begin{abstract}
The endothelial dysfunction has been implicated as a major event in the pathogenesis of atherosclerosis. Therefore, this study was planned to determine (a) role of endothelium-derived nitric oxide (NO) and endothelin as coronary artery disease (CAD) risk markers and (b) intergenotypic variation of endothelial nitric oxide synthase (eNOS) Glu298Asp polymorphism in CAD.The endothelin, NO and eNOS genotypes were determined in 60 patients with documented history of CAD. These were compared with 50 age- and sex- matched healthy controls. The genotype frequencies for eNOS gene polymorphism were determined by PCR and RFLP. The plasma endothelin in CAD patients was significantly higher $(p<0.001)$ whereas, the NO level in CAD group was significantly lower $(p<0.001)$ than the control group. The genotype frequencies for Glu298/Asp (Glu/Glu and Glu/Asp) genotypes were $75 \%$ and $25 \%$ in CAD subjects and $88 \%$ and $12 \%$ in control subjects, respectively. No Asp/Asp was found in any of the groups. The genotype frequencies differed significantly $(p<0.05)$ between the controls and cases. In conclusion, endothelin and NO may be used as markers of endothelial dysfunction in CAD. Asp allele might be a risk factor for $\mathrm{CAD}$ in the North Indian population.
\end{abstract}

Keywords: Nitric oxide, Coronary artery disease, Glu298Asp polymorphism, endothelin

\section{Introduction}

Coronary artery disease (CAD) is described as our modern "epidemic". By 2015, this is expected to account for $34 \%$ of all male deaths and $32 \%$ of all female deaths in India [1]. Studies suggest that most CAD event rates are noted in individuals with one or more CAD risk factors [2]. However, at least 25 percent of coronary patients have sudden death or myocardial infarction without prior symptoms [3]. Hence, there is a need to focus attention on additional markers to predict coronary risk. It is well accepted that endothelial dysfunction occurs in response to cardiovascular risk factors and precedes the development of atherosclerosis [4]. Therefore, in this study, we have investigated

* Address for correspondence: Dr. Vandana Saini, A-2/608, MilanVihar apartments, I.P. Extension, Patparganj, New Delhi-110092, India. E-mail: vandanasaini2@gmail.com. some of the factors which are considered to play a pivotal role in the maintaining endothelial homeostasis nitric oxide (NO), endothelium derived bioactive peptide endothelin and G894T variant of endothelial nitric oxide synthase (eNOS) gene polymorphism.

Nitric oxide is one of the most important products synthesized by NO synthase (NOS) of endothelial cells, a signaling molecule that is able to exert profound functional and morphological effects on the vascular wall. Several experimental studies have demonstrated that NO inhibits many key steps of the atherosclerotic disease, and a defect of NO production could facilitate the progression of the atherosclerotic process [5]. NO generation is regulated through alterations in the expression of the eNOS enzyme. Due to the protective role of NO, the eNOS gene has gained special importance in the pathogenesis of CAD [6]. Further, the associations between eNOS genotypes and vascular disease could be population and disease specific. Functional DNA variants such as GT or TT alleles in the eNOS gene can 
lead to changes in the eNOS expression and enzyme activity, which may be modified by environmental factors. Understanding the nature of interaction will not only predict those at high risk for genotype-determined CAD risk, it will also build up interventional strategies.

eNOS is a key enzyme involved in maintenance of vascular homeostasis. A common variant located in exon $7\left(\mathrm{G}^{894} \mathrm{~T}\right)$ of the eNOS gene that modifies its coding sequence (Glu ${ }^{298} \mathrm{Asp}$ ) has been linked by several groups to the risk for coronary spasm, CAD, and acute myocardial infarction [7-9]. Some studies failed to find any relationship between the Asp variant and the risk of atherosclerosis $[10,11]$ whereas other found that the risk for CAD is confined to individuals homozygous for the Asp allele of the $\mathrm{Glu}^{298}$ Asp polymorphism, suggesting that homozygosity for aspartic acid in position 298 could produce a significant decrease in the amount of eNOS or its enzymatic activity [7,9].

Endothelin, a marker of endothelial function and a potent vasoconstrictor peptide, induces smooth muscle cell proliferation and synthesis of extracellular matrix substances [12]. Increased plasma endothelin level may indicate early disturbances of endothelial function. Experimental studies have shown that endothelin may be produced by activated human macrophages and has also been implicated in cytokine and vascular cell adhesion molecule expression [13].

Here, we have investigated the role of emerging biomarkers of endothelial dysfunction that may increase the predictability of a coronary event in Indian population.

\section{Materials and methods}

This study was conducted in a tertiary care hospital of northern India and included 110 subjects (60 cases and 50 controls), after being approved by the ethical committee of the institution. Informed consent was taken from all the participants. Patients with documented history of coronary artery disease (on the basis of ECG and coronary angiography) were selected from the Out Patient Department of Medicine, Lady Hardinge Medical College and associated hospitals, New Delhi. Age and sex matched controls comprised of healthy volunteers with no clinical or ECG evidence of CAD and negative history of major CAD risk factors (past event of CAD or stroke, Diabetes Mellitus, hypertension, smoking, dyslipidemia and family history of CAD). Patients with recent history of acute coronary syndrome or cerebrovascular event ( $<8$ weeks), chronic liver and kidney disease and cancer were excluded from the study. $5 \mathrm{ml}$ of overnight fasting blood sample was collected from all study participants, by venipuncture into evacuated tubes. Plasma obtained after centrifugation ( $10 \mathrm{~min}$ at $2500 \mathrm{x} \mathrm{g}$ ), was divided into 2 aliquots- one for NO evaluation and second for endothelin. The remaining cell aggregrate was kept for genotyping. Aliquots were stored at $-40^{\circ} \mathrm{C}$ until batch analysed.

\subsection{Estimation of $\mathrm{NO}$}

Determination of NO in plasma was performed indirectly by the measurement of stable decomposition product nitrite $\left(\mathrm{NO}_{2}\right)$, employing the Griess reaction (Mathew et al. (1996) [14]. Nitrite can be directly detected by observing the magenta colored azo dye that is formed from nitrite $\left(\mathrm{NO}_{2}\right)$ and the Griess reagent, the absorbance of which was determined at $543 \mathrm{~nm}$ using semiautoanalyser.

\subsection{Estimation of endothelin}

Plasma endothelin was estimated by ELISA using DRG's human Endothelin-1 Enzyme Immunometric Assay kit. The color generated was read at $450 \mathrm{~nm}$. The measured optical density was directly proportional to the concentration of endothelin.

\subsection{Genotyping}

The DNA Extraction was done using Bioneer Genomic DNA Extraction Kit. This DNA was amplified by PCR using primers flanking polymorphic region of eNOS gene(Fig. 1). The resulting 457-bp amplification product was digested with Ban II restriction enzyme at $37^{\circ} \mathrm{C}$ for 20 hours. Ban II digested the amplified fragments into smaller fragments (137 bp and $320 \mathrm{bp}$ ) (Fig. 2). In case of a $\mathrm{G}$ to $\mathrm{T}$ substitution at position 894 of the exon 7 of eNOS gene, a Ban II restriction site was lost.The restricted fragments were resolved on $2 \%$ agarose gels and visualized by ethidium bromide staining.

\section{Statistical analysis}

Statistical analysis was done using SPSS version 14.0 software programme. The variables between patients and controls were compared using Student's t test and Chi square test. 'p' values below 0.05 were considered significant. All values are expressed in mean \pm standard error of mean. 


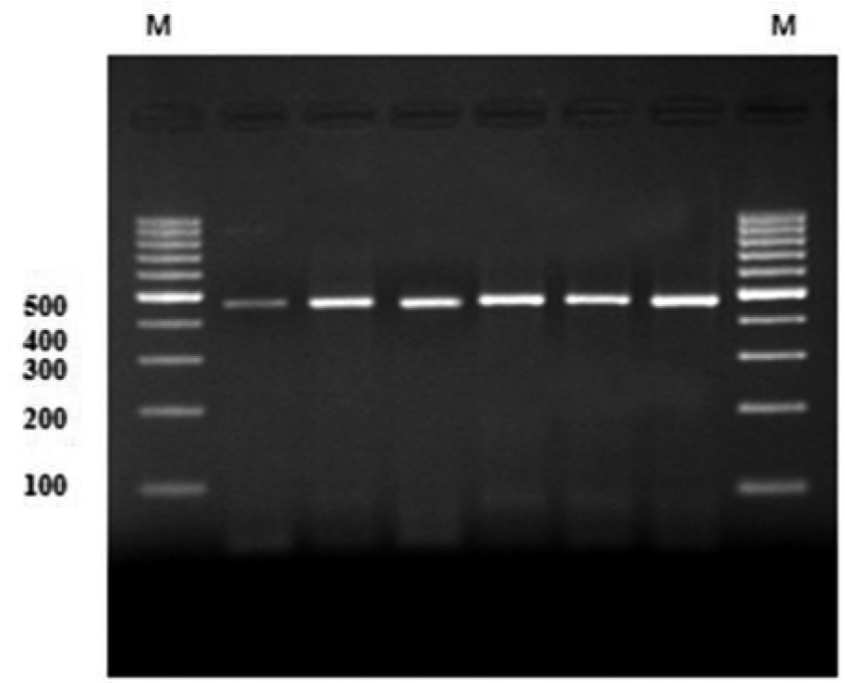

Fig. 1. Ethidium bromide-stained agarose gel used for genotyping PCR products (457 bp) with primers flanking Glu298 Asp polymorphic region of eNOS gene. (M-molecular wt. marker).

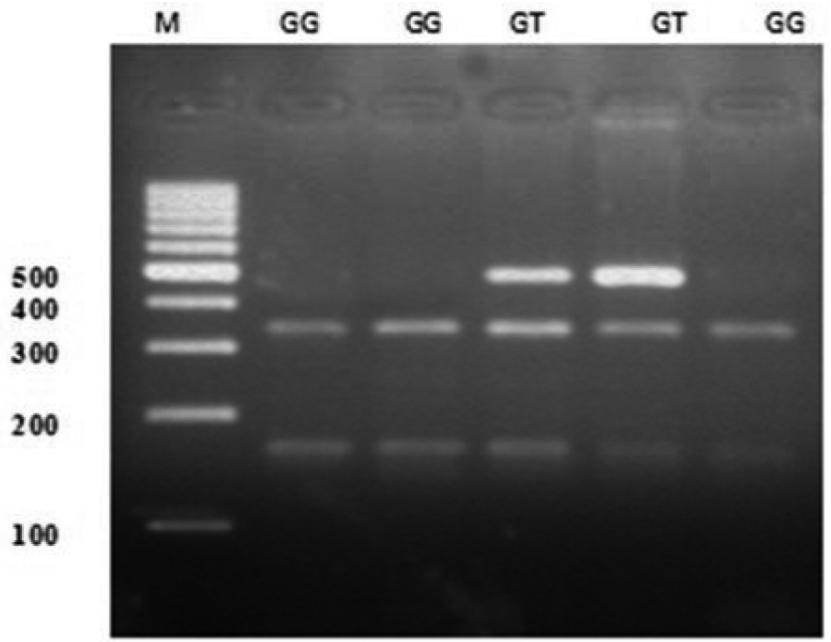

Fig. 2. eNOS gene digested with BanII restriction enzyme. Homozygotes (GG) showed 2 bands at 320 bp and 137 bp. Heterozygotes for this mutation(GT) showed 3 bands at $457 \mathrm{bp}, 320 \mathrm{bp}$, and $137 \mathrm{bp}$.

\section{Results}

The study and the control group were age- and sexmatched. The demographic and biochemical characteristics of the study population are shown in Table 1 and 2 respectively. The mean age of the patients in the study group was $59.46 \pm 11.334$ years. The study population consisted of $58 \%$ females and $42 \%$ males. Hypertension and Diabetes mellitus were present in $70 \%$ and $36 \%$ of the study group, respectively, followed by hypertriglyceridemia (34\%) and smoking (26\%).
Plasma NO and endothelin levels in the study and the control group are shown in Table 3. The NO level was found out to be significantly lower in the CAD group than in the control group $(p<0.001)$ whereas endothelin was significantly higher in the CAD patients as compared to the healthy controls $(p<0.001)$.

The distribution of genotypes of the Glu298Asp polymorphism is shown in Table 4. GG genotype was found in 45 subjects $(75 \%)$ of study group and 44 subjects $(88 \%)$ in the control group. GT genotype was found in 15 subjects $(25 \%)$ of study group and 6 subjects $(12 \%)$ of the control group. No TT was found in 
Table 1

Demographic characteristics of CAD patients and controls

\begin{tabular}{lccr}
\hline Demographic factors & Cases $(n=60)$ & Controls $(n=50)$ & p value \\
\hline Age(years) & $59.46 \pm 1.603$ & $58.32 \pm 1.667$ & 0.623 \\
Diabetics $\%$ & 36 & - & $<0.001$ \\
Hypertension $\%$ & 70 & - & $<0.001$ \\
Smokers\% & 26 & - & $<0.001$ \\
Hypertriglyceridemia $(>150 \mathrm{mg} / \mathrm{dl}) \%$ & 34 & - & $<0.001$ \\
Hypercholesterolemia( $>200 \mathrm{mg} / \mathrm{dl}) \%$ & 22 & - & $<0.001$ \\
Family history of CAD \% & 18 & $22.836 \pm 0.637$ & 0.340 \\
BMI $(\mathrm{kg} / \mathrm{m} 2)$ & $23.672 \pm 0.643$ & & \\
\hline
\end{tabular}

Values are represented as mean \pm standard error of mean.

Table 2

Biochemical characteristics of CAD patients and controls

\begin{tabular}{lccc}
\hline Parameters & Cases $(n=60)$ & Controls $(n=50)$ & p value \\
\hline Total Cholesterol(mg/dl) & $167.80 \pm 5.997$ & $169.30 \pm 3.006$ & 0.890 \\
Triglycerides (mg/dl) & $133.62 \pm 8.701$ & $129.12 \pm 3.846$ & 0.537 \\
HDL-C (mg/dl) & $29.90 \pm 1.372$ & $40.82 \pm 0.882$ & 0.001 \\
LDL-C (mg/dl) & $110.20 \pm 5.356$ & $103.00 \pm 2.943$ & 0.245 \\
LDL-C/HDL-C & $4.193 \pm 0.311$ & $2.597 \pm 0.109$ & 0.001 \\
FBS(mg/dl) & $104.20 \pm 7.238$ & $82.28 \pm 1.188$ & 0.001 \\
Urea (mg/dl) & $33.62 \pm 1.720$ & $30.10 \pm 1.058$ & 0.205 \\
Creatinine(mg/dl) & $0.968 \pm 0.039$ & $0.824 \pm 0.027$ & 0.003 \\
Uric Acid (mg/dl) & $4.594 \pm 0.163$ & $4.864 \pm 0.192$ & 0.271 \\
Bilirubin (mg/dl) & $0.754 \pm 0.045$ & $0.586 \pm 0.027$ & 0.008 \\
ALT (IU/L) & $30.74 \pm 1.713$ & $29.08 \pm 1.938$ & 0.307 \\
AST (IU/L) & $36.24 \pm 2.925$ & $29.70 \pm 2.348$ & 0.086 \\
ALP(IU/L) & $140.58 \pm 5.56$ & $128.62 \pm 4.401$ & 0.120 \\
Total protein (g/dl) & $6.88 \pm 0.124$ & $7.00 \pm 0.097$ & 0.612 \\
Albumin(g/dl) & $3.724 \pm 0.076$ & $3.810 \pm 0.124$ & 0.923 \\
\hline
\end{tabular}

any group. The odd's ratio of the GT genotype in cases was 2.44 which was significantly high.

Table 5 shows the intergenotypic variation of the plasma nitric oxide and endothelin levels in the CAD and control group. NO level was found to be significantly lower in the GT genotype of both study and control group. Also, the NO level was significantly lower in the in the GG genotype of CAD group as compared to the controls.

\section{Discussion}

CAD is a major cause of mortality and morbidity around the world. The fact that traditional risk factors have failed to explain the excess risk of CAD has raised the possibility of a genetic susceptibility among Asian Indians [15]. We attempted to investigate the frequency of eNOS Glu298Asp polymorphism along with usefulness of some novel biomarkers in patients of CAD.

The mean age of the patients in the CAD group was $59.46 \pm 11.33$ years. It was found that $61-70$ years age group had highest occurence $(34 \%)$ of CAD events followed by 40-50 years age group (32\%). This shows that though the occurrence of a CAD event is more common in elderly population, however the incidence is also increasing at an earlier age in Indian population. The study population consisted of $58 \%$ females and $42 \%$ males. $82 \%$ of the females were postmenopausal. As seen in many observational studies, menopausal women have higher risk of CAD [16]. The estrogen deprivation may be related to accelerating the risk atherosclerotic process after menopause [16]. The distribution of risk factors among the study group (Table 1) showed that hypertension $(70 \%)$ and Diabetes mellitus(36\%) were the most prevalent risk factors in CAD patients correlating with the earlier findings that hypertension and Diabetes are associated with marked increase in the risk of CAD [17-19]. There was no significant difference in the BMI between patients and controls (Refer Table 1). BMI of the entire study group (patients and controls) fell in the upper part of the normal range $\left(18-25 \mathrm{~kg} / \mathrm{m}^{2}\right)$ indicating an increased susceptibility towards disease [20]. There was a significant difference $(p<0.001)$ in the mean fasting blood sugar level of the study and control groups (Table 2). This may be due to the fact that $36 \%$ of the study pop- 
ulation were diabetic with or without medication. The difference between the mean HDL level and LDL/HDL ratio was also highly significant $(p<0.001)$. Lipoprotein profile is deranged in large proportion of CAD patients [21]. Low HDL and high LDL/HDL ratio has been associated with increased risk of CAD in many studies [22]. Low levels of HDL-C are reported to increase the risk of CAD even when total cholesterol is not elevated [23].

The mean plasma endothelin level in the CAD group was $9.78 \pm 2.838 \mathrm{pg} / \mathrm{ml}$ and in the control group was $7.86 \pm 2.204 \mathrm{pg} / \mathrm{ml}$. The difference between the two was highly significant $(p<0.001)$. Increased plasma endothelin levels may indicate early disturbances of endothelial function. Endothelin is a potent vasoconstrictor, promotes smooth muscle cell proliferation and the synthesis of extracellular matrix substances. These factors play a major role in the pathogenesis of atherosclerotic process. Further to its vasoconstrictor and mitogenic properties, endothelin appears to be involved in the inflammatory process that underlies active atheromatous plaques [13]. According to Zouridakis et al. [24], plasma endothelin was raised in patients with coronary artery disease progression and may be a marker of risk of rapid stenosis progression. Significantly increased plasma concentrations were also found in patients with CAD, with the highest levels in a subgroup of 8 patients presenting with unstable angina [25]. In a recent study [26], the endothelin activity level was significantly elevated in subjects with significant obstructive CAD.Furthermore, high endothelin activity level was found to correlate with calcified plaque burden and to be an independent determinant of lesion of plaque severity.

Nitric oxide inhibits many key steps of the atherosclerotic disease. The fact that in a rabbit model, long term systemic inhibition of NO production with the NOS inhibitor L-NAME $\left(\mathrm{N}^{G}\right.$ - nitro- $\mathrm{L}$ arginine methyl ester) [27], enhances the formation of early atherosclerotic lesions further reinforces the protective role of $\mathrm{NO}$ in CAD. NO is a potent vasodilator. Besides, it also plays a major role in the inhibition of platelet adhesion and aggregation [28], of adhesion molecule and chemokine expression [29], of inflammatory cell infiltration [30] and, of smooth muscle cell proliferation [31]. A significant decrease in the NO level in atherosclerotic vessels may be due to oxidative stress in CAD. Increased superoxide production reacts rapidly with NO producing peroxynitrite which causes oxidative tissue damage by nitrosylation. Thus, endothelial function is impaired in CAD patients which may play a role in the pathogenesis
Table 3

Plasma NO and Endothelin level in the CAD and Control group

\begin{tabular}{lcr}
\hline & CAD & \multicolumn{1}{c}{ Control } \\
\hline NO $(\mu \mathrm{mol} / \mathrm{L})$ & $11.56 \pm 1.151^{*}$ & $16.98 \pm 1.248$ \\
Endothelin $(\mathrm{pg} / \mathrm{ml})$ & $* 9.78 \pm 0.401^{*}$ & $7.86 \pm 0.312$ \\
\hline$*(p<0.001)$. & &
\end{tabular}

of cardiovascular events [32]. In the present study, the mean plasma NO level was significantly lower in CAD group $(11.56 \pm 8.137 \mu \mathrm{mol} / \mathrm{L})$ than in control group $(16.98 \pm 8.826 \mu \mathrm{mol} / \mathrm{L})$. The difference between the two was highly significant $(p<0.001)$. Thus, our study interprets that NO has an antiatherogenic effect in the vasculature. Moreover, median plasma NO was found to be significantly higher in CAD patients than in controls in a study by Yoon et al. [33]. A recent study also showed significant low values of NO in non-smoking and non-diabetic patients of CAD as compared to controls [32].

Since NO availability is regulated at the level of synthesis, the gene that encodes eNOS is a candidate for cardiovascular disease [34]. Several eNOS gene polymorphisms have been reported as 'susceptibility genes' in various cardiovascular and pulmonary diseases [35] of which we have studied Glu298Asp. This polymorphism is associated with CAD, end stage renal disease, and diabetic nephropathy in some [9,36-38] but not all studies [39-41]. The Asp allele from the Glu298Asp polymorphism was found to be an independent risk factor for premature ST elevation acute myocardial infarction in Mexican population [42]. However, in a study in Turkish population, neither the frequencies of the Glu298Asp genotypes nor the serum nitric oxide levels showed a significant difference between the patient and control groups [43].

In our study, GT genotype was more commonly present in patients of $\operatorname{CAD}(25 \%)$ as compared to the controls $(12 \%)$. No TT was found in any group. The genotype frequencies differed significantly $(p<0.05)$ between the controls and cases showing that $\mathrm{T}$ allele may be the susceptibility allele for CAD in Indian population. Not much study has been done in India regarding eNOS Glu298Asp polymorphism genotype and allelic distribution in CAD patients. Kamna et al. [44] studied the prevalence of eNOS Glu298Asp polymorphism in 139 healthy volunteers from a region of Northern India. The distribution of GG, GT and TT genotypes was found to be $71.22 \%, 28.06 \%$ and $0.72 \%$ respectively and the allelic frequency of $\mathrm{G}$ and $\mathrm{T}$ allele were 0.853 and 0.148 respectively. In a recent study done in South Indian population, the genotype frequen- 
Table 4

Genotype frequencies of Glu298Asp polymorphism in CAD patients and controls

\begin{tabular}{lccl}
\hline Genotypes & Patients $(n=60)$ & Control $(n=50)$ & Odd's ratio \\
\hline Glu/Glu & $45(75 \%)$ & $44(88 \%)$ & 0.408 \\
Glu/Asp & $15(25 \%)$ & $6(12 \%)$ & 2.44 \\
Asp/Asp & 0 & 0 & 0 \\
\hline
\end{tabular}

Table 5

Intergenotypic variation of the plasma NO and endothelin level in CAD and control group

\begin{tabular}{|c|c|c|c|c|}
\hline \multirow[t]{2}{*}{ Genotype } & \multicolumn{2}{|c|}{ Nitric oxide $(\mu \mathrm{mol} / \mathrm{L})$} & \multicolumn{2}{|c|}{ Endothelin (pg/ml) } \\
\hline & CAD & Control & CAD & Control \\
\hline $\mathrm{GG}+\mathrm{GT}$ & $11.56 \pm 1.15^{* *}$ & $16.98 \pm 1.25$ & $9.78 \pm 0.401^{* *}$ & $7.86 \pm 0.312$ \\
\hline GG & $12.64 \pm 1.38^{*}$ & $17.68 \pm 1.37$ & $9.79 \pm 0.46^{* *}$ & $7.81 \pm 0.32$ \\
\hline GT & $7.73 \pm 1.34$ & $11.83 \pm 1.58$ & $9.72 \pm 0.81$ & $8.17 \pm 1.13$ \\
\hline
\end{tabular}

cies for Glu298/Asp (Glu/Glu, Glu/Asp and Asp/Asp) genotypes were $46.83 \%, 30.37 \%$ and $22.78 \%$ in CAD subjects and $60.75 \%, 31.64 \%$ and $7.59 \%$ in control subjects, respectively, the distribution of which was significant $(p<0.05)$ between the controls and cases [45]. Some studies have recently shown that Asp allele is subjected to selective proteolytic cleavage in endothelial cells and vascular tissues [46,47] which may be responsible for the $\mathrm{T}$ allele being the risk factor for CAD.

In our study, it was found that in both CAD and control group, the mean NO level was significantly lower in GT genotype as compared to GG genotype. This shows that the T allele may be the susceptibility marker for endothelial dysfunction seen in CAD. We also demonstrated a significant decrease in plasma NO levels $(p<0.01)$ in the GG genotype of the CAD group $(12.641 \pm 8.643 \mu \mathrm{mol} / \mathrm{L})$ as compared to the $\mathrm{GG}$ genotype of the control group $(17.681 \pm 9.1 \mu \mathrm{mol} / \mathrm{L})$. Again in the GT genotype, the mean NO levels in the CAD group were lower $(7.727 \pm 4.452 \mu \mathrm{mol} / \mathrm{L})$ than in the control group $(11.833 \pm 3.868 \mu \mathrm{mol} / \mathrm{L})$. Moreover, plasma endothelin was found to be significantly higher in the GG genotype of the CAD patients as compared to the controls. This may interpret that there are certain factors other than the genetic predisposition also which are also responsible for the occurrence of CAD.

Thus, in conclusion, our study finds that endothelin and NO may be used for risk assessment especially in premature $\mathrm{CAD}$ and in individuals where traditional risk factors are not present. A significant association has been found between Glu298Asp polymorphism and $\mathrm{CAD}$. Though the $\mathrm{T}$ allele is more frequently present in the CAD patients, further studies are also suggested for the conclusive evidence.

\section{Acknowlegements}

This study has received grant support from Indian Council of Medical Research(ICMR).

\section{References}

[1] K.S. Reddy and Y. Salim, Emerging epidemic of cardiovascular disease in developing countries, Circulation 97 (1998), 596-601.

[2] S. Vas Ramachandran et al., Relative importance of borderline and elevated levels of coronary heart disease risk factors, Annals of Internal Medicine 142(6) (2005), 1515-1520.

[3] P. Greenland, S.C. Smith, Jr. and S.M.Grundy, Role of traditional risk factors and noninvasive cardiovascular testsimproving coronary heart disease risk assessment in asymptomatic people, Circulation 104 (2001), 1863-1867.

[4] R. Ross, Atherosclerosis: an inflammatory disease, $N$ Engl J Med 340 (1999), 115-126.

[5] J.P. Cooke, Role of nitric oxide in progression and regression of atherosclerosis, West J Med 164 (1996), 419-424.

[6] Y. Yoon, J. Song, S.H. Hong and J.Q. Kim, Plasma nitric oxide concentrations and nitric oxide synthase gene polymorphisms in coronary artery disease, Clin Chem 46 (2000), 1626-1630.

[7] A.D. Hingorani, C.F. Liang, J. Fatibene, A. Lyon, S. Monteith, A. Parsons et al., A common variant of the endothelial nitric oxide synthase (Glu298Asp) is a major risk factor for coronary artery disease in the UK, Circulation 100 (1999), 1515-1520.

[8] K. Hibi, T. Ishigami, K. Tamura, S. Mizushima, N. Nyui, T. Fujita et al., Endothelial nitric oxide synthase gene polymorphism and acute myocardial infarction, Hypertension 32 (1998), 521-526.

[9] M.G. Colombo, M.G. Andreassi, U. Paradossi, N. Botto, S. Manfredi, S. Masetti et al., Evidence for association of a common variant of the endothelial nitric oxide synthase gene (Glu ${ }^{298}$ Asp polymorphism) to the presence, extent and severity of coronary artery disease, Heart 87 (2002), 525-528.

[10] H. Cai, D.E. Wilcken and X.L. Wang, The Glu298Asp (894GT) mutation at exon 7 of the endothelial nitric oxide synthase gene and coronary artery disease, J Mol Med 77 (1999), 511-514. 
[11] H.S. Markus, Y. Ruigrok, N. Ali and J.F. Powell, Endothelial nitric oxide synthase exon 7 polymorphism, ischemic cerebrovascular disease, and carotid atheroma, Stroke 29 (1998), 1908-1911.

[12] F. Martin-Nizard, C. Furman, P. Delerive, A. Kandoussi, J.C. Fruchart, B. Staels and P. Duriez, Peroxisome proliferateactivated receptor activators inhibit oxidized low density lipoprotein-induced endothelin-1 secretion in endothelial cells, Journal of Cardiovascular Pharmacology 40 (2002), 822-883.

[13] A.M. Zeiher, H. Goebel, V. Schachinger and C. Ihling, Tissue endothelin-1 immunoreactivity in the active coronary atherosclerotic plaque. A clue to the mechanism of increased vasoreactivity of the culprit lesion in unstable angina, Circulation 91 (1995), 941-947.

[14] F. Mathew, J. Glenda and L. Jack, Quantification of nitric and nitrate in extracellular fluids, Metho Enzymol 268 (1996), 237-246.

[15] M. Viswanathan, D. Raj, H.S. Prasanth, P. Gopal, M. Rema and A. Enas, Lipoprotein(a) is an independent risk factor for coronary artery disease in NIDDM patients in South India, Diabetes Care 21 (1998), 1819-1823.

[16] K. Braunwald, F. Hauseer and L. Jameson, Prevention and treatment of atherosclerosis, in: Harrison principles of Internal Medicine (16 edition) ed., 2005, pp. 1425-1432.

[17] K. Park, Epidemiology of chronic non communicable diseases and conditions, in: Preventive and Social Medicine (18 edition) (2005), pp. 287-288.

[18] J. Davingnon and J.S. Cohn, Triglycerides: a risk factor for coronary heart disease, Atherosclerosis 124 (1996), S57-S64.

[19] J. Stamler, O. Vaccaro, J.D. Neaton and D. Wentworth, Diabetes, other risk factors, and 12-yr cardiovascular mortality for men screened in the Multiple Risk Factor Intervention Trial, Diabetes Care 16 (1993), 434-444.

[20] B. Archana, J. Kajal, R. Gulati, V. Chopra, D.P. Agarwal and S. Vasisht, Lipoprotein(a) as a marker of coronary artery disease and its association with dietary fat, JAPI 52 (2004), 99-102.

[21] G. Utermann, The mysteries of lipoprotein(a), Science $\mathbf{2 4 6}$ (1989), 904-910.

[22] A. Ramachandran, I. Sathyamurthy, C. Snehalatha et al., Risk variables for coronary artery disease in Asian Indians, Am J Cardiol 87 (2001), 267-271.

[23] J.K. Gambhir, K. Harsimrut, D.S. Gambhir and K.M. Prabhu, Lipoprotein(a) as an independent risk factor for Coronary artery disease in patients below 40 years of age, Ind Heart $J$ 52 (2000), 411-415.

[24] E.G. Zouridakis, R. Schwartzman, X. Garcia-Moll, I.D. Cox, S. Fredericks, D.W. Holt and J.C. Kaski, Increased plasma endothelin levels in angina patients with rapid coronary artery disease progression, European Heart Journal 22 (2000), 1578-1584.

[25] R.M. Arendt, U. Wilbert-Lampen, L. Heucke, M. Schmoeckel, K. Sühler and W.O. Richter, Increased endothelin plasma concentrations in patients with coronary artery disease or hyperlipoproteinemia without coronary events, Research in Experimental Medicine 193 (1993), 225-230.

[26] E. Goldhammer,Y.B. Moshe, A. Lubovich, Y. Rivlin, I. Maor, R. Zeina and U. Rosenchein, erum endothelin-1,MMP-9, and myeloperoxidase and coronary artery morphologyas detected by multi-slice CT angiography in intermediate and high risk asymptomatic subjects, The Open Biomarkers Journal 3 (2010), 7-12.

[27] A. Cayatte, J. Palacino, K. Horten and R.A. Cohen, Chronic inhibition of nitric oxide production accelerates neointima formation and impairs endothelial function in hypercholesterolaemic rabbits, Arterioscler Thromb Vasc Biol 14 (1994), 753-759.

[28] D.I. Simon, J.S. Stamler, O. Jaraki, J.F. Keaney, J.A. Osborne, S.A. Francis, D.J. Singel and J. Loscalzo, Antiplatelet properties of protein S-nitrosothiols derived from nitric oxide and endothelium-derived relaxing factor, Arterioscler Thromb 13 (1993), 791-799.

[29] R. De Caterina, P. Libby, H.-B. Peng, V.J. Thanniekal, T.B. Rajavashisth, M.A. Gimbrone, Jr., W.S. Shin and J.K. Liao, Nitric oxide decreases cytokine-induced endothelial activation: nitric oxide selectively reduces endothelial expression of adhesion molecules and proinflammatory cytokines, J Clin Invest 96 (1995), 60-68.

[30] A.M. Zeiher, B. Fisslthaler, B. Schray-Utz and R. Busse, Nitric oxide modulates the expression of monocyte chemoattractant protein I in cultured human endothelial cells, Circ Res $\mathbf{7 6}$ (1995), 980-986.

[31] R. Sarkar, E.G. Meinberg, J.C. Stanley, D. Gordon and R.C. Webb, Nitric oxide reversibly inhibits the migration of cultured vascular smooth muscle cells, Circ Res 78 (1996), 225-230.

[32] A.K. Shaikh and A.N. Suryakar, Oxidative stress, endothelial dysfunctionand status of L-arginine and nitric oxide in coronary artery disease, Biomedical Research 19 (2008), 211-214.

[33] Y. Yoon, J. Song, S.H. Hong and J.Q. Kim, Plasma Nitric Oxide Concentrations and Nitric Oxide Synthase Gene Polymorphisms in Coronary Artery Disease, Clinical Chemistry 46 (2000), 1626-1630.

[34] A.D. Hingorani, Polymorphisms in endothelial nitric oxide synthase and atherogenesis: John French Lecture 2000, Atherosclerosis 154 (2001), 521-527.

[35] B.C. Kone, Molecular biology of natriuretic peptides and nitric oxide Synthase, Cardiovasc Res 51 (2001), 429-441.

[36] G. Lembo, L.N. De, C. Battagli, G. Iovino, A. Aretini, M. Musicco, G. Frati, F. Pompeo, C. Vecchione and B. Trimarco, A common variant of endothelial nitric oxide synthase (Glu298Asp) is an independent risk factor for carotid atherosclerosis, Stroke 32 (2001), 735-740.

[37] E. Noiri, H. Satoh, J. Taguchi, S.V. Brodsky, A. Nakao, Y. Ogawa, S. Nishijima, T. Yokomizo, K. Tokunaga and T. Fujita, Association of eNOS Glu298Asp polymorphism with endstage renal disease, Hypertension 40 (2002), 535-540.

[38] S. Nagase, H. Suzuki, Y. Wang, S. Kikuchi, A. Hirayama, A. Ueda, K. Takada, T. Oteki, M. Obara, K. Aoyagi and A. Koyama, Association of eNOS gene polymorphisms with end stage renal diseases, Mol Cell Biochem 244 (2003), 113-118.

[39] J. Karvonen, H. Kauma, K. Kervinen, M. Rantala, M. Ikaheimo, M. Paivansalo, M.J. Savolainen and Y.A. Kesaniemi, Endothelial nitric oxide synthase gene Glu298Asp polymorphism and blood pressure, left ventricular mass and carotid artery atherosclerosis in a population-based cohort, J Intern Med 251 (2002), 102-110.

[40] I. Schmoelzer, W. Renner, B. Paulweber, L. Malaimare, B. Iglseder, P. Schmid, K. Schallmoser and T.C. Wascher, Lack of association of the Glu298Asp polymorphism of endothelial nitric oxide synthase with manifest coronary artery disease, carotid atherosclerosis and forearm vascular reactivity in two Austrian populations, Eur J Clin Invest 33 (2003), 191-198.

[41] A. Zanchi, D.K. Moczulski, L.S. Hanna, M. Wantman, J.H. Warram and A.S. Krolewski, Risk of advanced diabetic nephropathy in type 1 diabetes is associated with endothelial nitric oxide synthase gene polymorphism, Kidney Int 57 (2000), 405-413. 
[42] I. Isordia-Salas, A. Leaños-Miranda and G. Borrayo-Sánchez, The Glu298ASP polymorphism of the endothelial nitric oxide synthase gene is associated with premature ST elevation myocardial infarction in Mexican population, Clin Chim Acta 411 (2010), 553-557.

[43] L. Afrasyap and G. Ozturk, NO Level and Endothelial NO Synthase Gene Polymorphism (Glu298Asp) in the Patients with Coronary Artery Disease from the Turkish Population, Acta Biochimica et biophysica sinica 36 (2004), 661-666.

[44] S. Kamna, B. Utpal, R. Narang, D. Nibhriti and V. Jacob, Prevalence of eNOS Glu298Asp polymorphism in healthy volunteers from a region of northern India, Community Genet $\mathbf{8}$ (2005), 180-183.
[45] R. Syed, M.U. Biyabani, S. Prasad, F. Deeba and K. Jamil, Evidence of association of a common variant of the endothelial nitric oxide gene polymorphism(Glu 298->Asp) to coronary artery disease in South Indian population, Journal of Medical Genetics and Genomics 3(1) (2011), 13-18.

[46] A. Persu, M.S. Stoenoiu, T. Messiaen et al., Modifier effect of eNOS in autosomal dominant polycystic kidney disease, Hum Mol Genet 11 (2002), 229-241.

[47] M. Tesauro, W.C. Thompson, P. Rogliani et al., Intracellular processing of endothelial nitric oxide synthase isoforms associated with differences in severity of cardiopulmonary diseases: cleavage of proteins with aspartate vs. glutamate at position 298, Proc Natl Acad Sci USA 6 (2000), 2832-2835. 


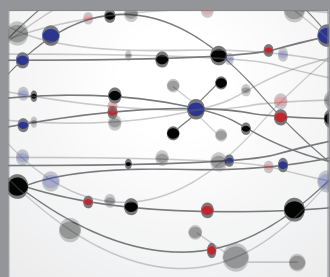

The Scientific World Journal
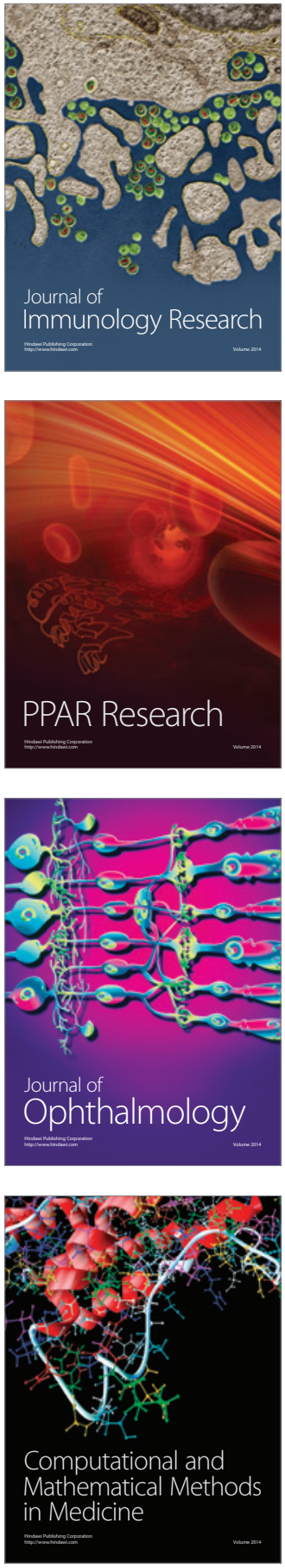

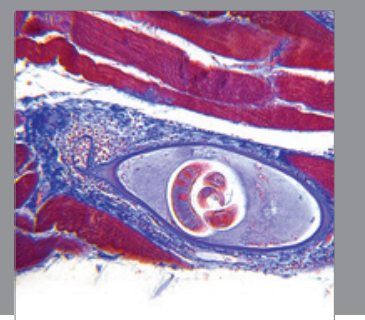

Gastroenterology

Research and Practice
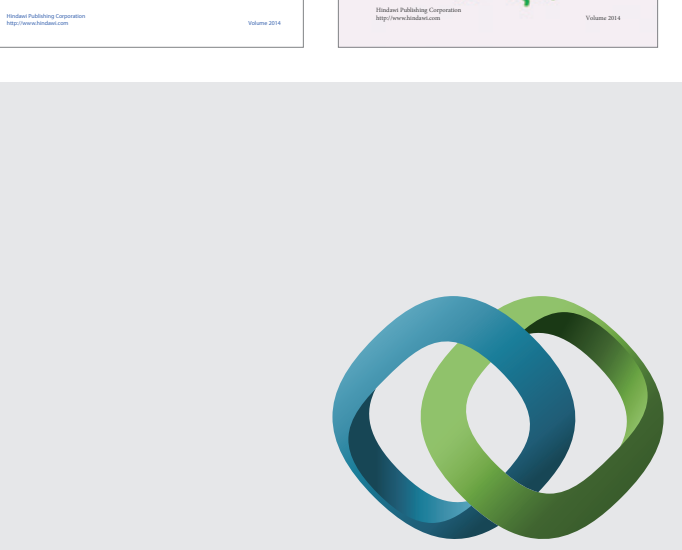

\section{Hindawi}

Submit your manuscripts at

http://www.hindawi.com
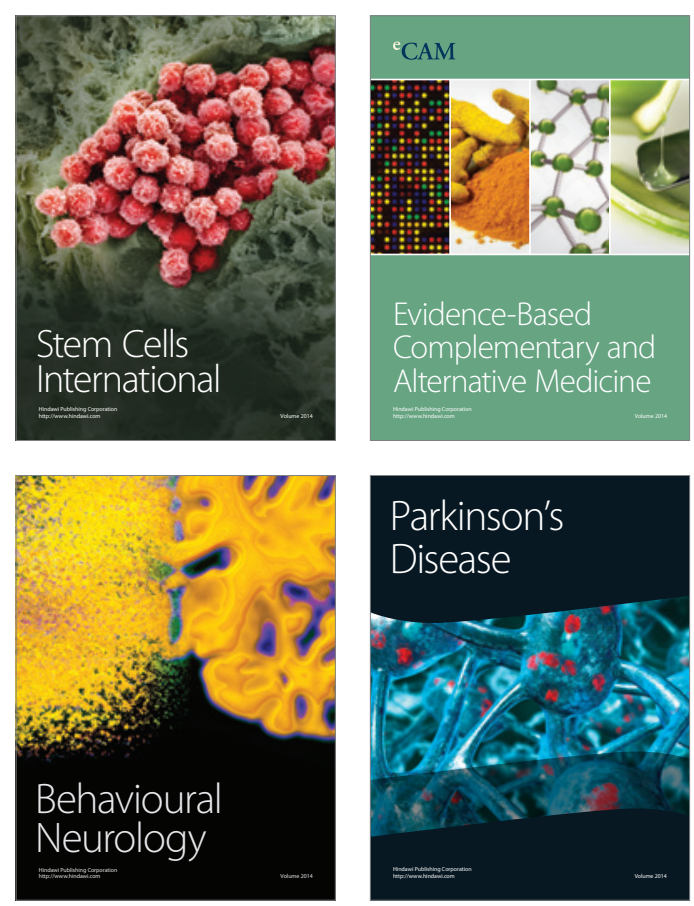

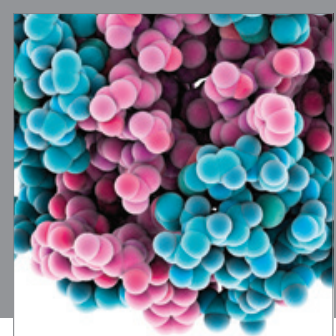

Journal of
Diabetes Research

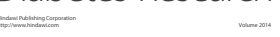

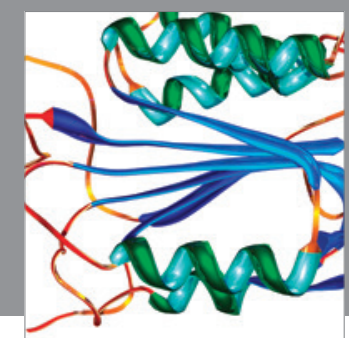

Disease Markers
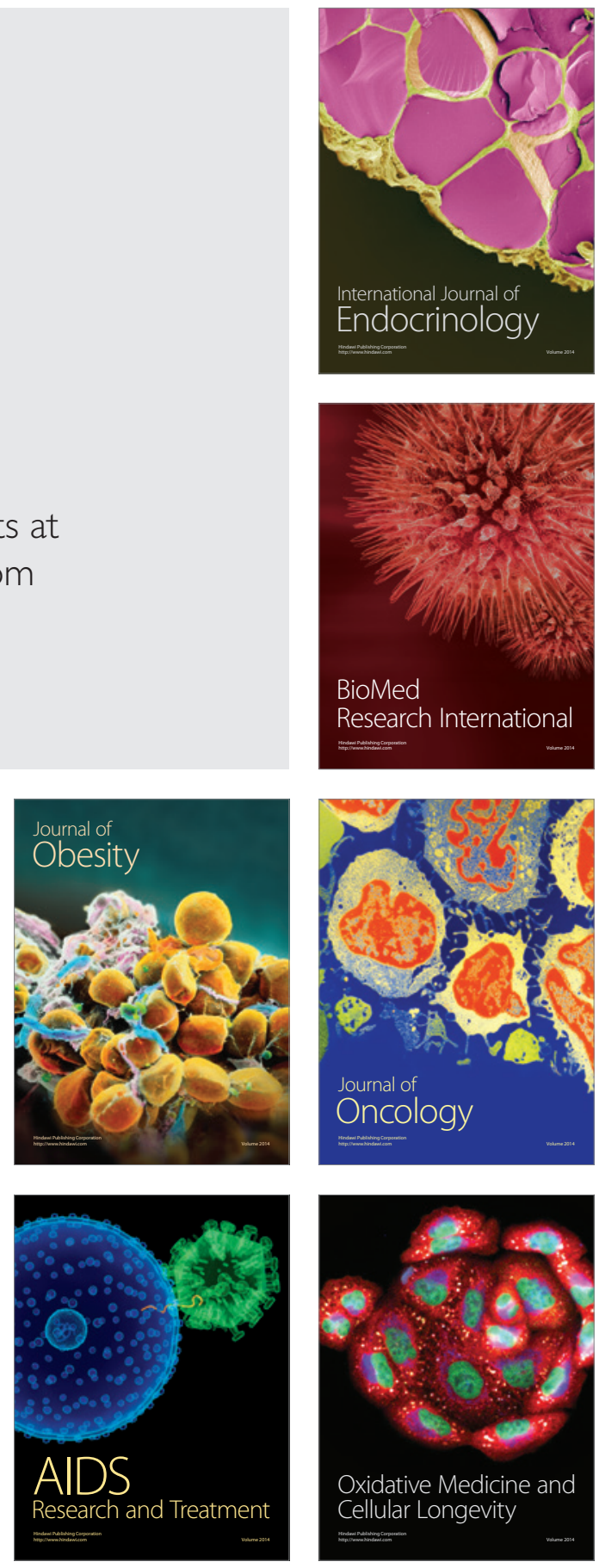